\title{
Pritchard, D. (2016). Epistemic Angst. Radical Skepticism and the Groundlessness of Our Believing. Princeton, Oxford: Princeton University Press.
}

\author{
Vicente Raga Rosaleny \\ Departamento de Filosofía \\ Facultad de Ciencias Humanas \\ Universidad Nacional de Colombia \\ Bogotá, Colombia \\ E-mail:vraga@unal.edu.co
}

Doi: $10.17533 / 10.17533 /$ udea.ef.n60a14

El libro Epistemic Angst (2016a) de Duncan Pritchard pretende, de acuerdo con una lectura predominante del pensamiento de Wittgenstein, curarnos de la angustia epistémica que producen las variedades más relevantes del escepticismo contemporáneo (Pritchard, 2016a). El libro tiene un interés innegable tanto para los que cultivan dicho campo de investigación como para los estudiosos del pensamiento tardío de Wittgenstein o para los que se sientan atraídos por una de las variantes más significativas de la teoría del conocimiento y la percepción actuales, el disyuntivismo epistémico, auspiciada de manera destacada por John McDowell (1995, por ejemplo). Adicionalmente, y de manera central, el volumen que reseñamos supone un gran aporte al vigente, y muy activo en los últimos tiempos, campo de la conocida como "epistemología de goznes", que desarrolla los supuestos epistémicos tan sólo esbozados en Sobre la certeza, obra póstuma compuesta a partir de los últimos cuadernos del ya mencionado Ludwig Wittgenstein. ${ }^{1}$ Finalmente, el libro tiene un gran atractivo por el modo en que dialoga críticamente con otros proponentes de dicha epistemología, así como con los defensores de respuestas alternativas al reto escéptico, bien sean internistas o externistas. $^{2}$

Una de las características más originales del libro del profesor Pritchard, evidenciada ya desde los primeros compases del texto, es su concepción de los retos escépticos contemporáneos bajo la forma de paradojas. De acuerdo con el

1 Sobre epistemología de goznes puede consultarse Wright (2004), así como Strawson (2003), Williams (1991) y más recientemente el volumen colectivo de Coliva \& Moyal-Sharrock (2016). La obra de Wittgenstein (1988) se cita por la versión española de Prades \& Raga.

2 Un buen resumen de éste lo encontramos en el propio Pritchard (2016b). Alston (1986) ofrece un adecuado panorama de las distintas posiciones internistas y externistas. 
autor, de hecho, las formulaciones más poderosas de los problemas escépticos parten de asunciones comunes, que todos pueden aceptar, pero desembocan en conclusiones inaceptables, como que no conocemos el mundo externo, abierto a los sentidos, y que los objetos de nuestras proposiciones comunes, constitutivas del conocimiento empírico ordinario, se encuentran bajo la sombra de una sospecha imposible de eliminar (p. 11).

Junto con esto, otra de las tesis fuertemente innovadoras del texto reseñado es su distinción entre dos variedades del escepticismo, formuladas de acuerdo con dos paradojas distintas $\mathrm{y}$ dependientes de principios diversos, que no deberían confundirse porque son lógicamente distintas. Más aún, una de las ideas principales del libro es que ambas paradojas escépticas encuentran respuesta en las propuestas epistémicas contemporáneas, pero las soluciones adecuadas no sirven indistintamente para una y otra paradoja, sino que responden a ellas de manera diferenciada. Aunque, y ésta es la conclusión central del autor, eso no significa que no puedan complementarse y reforzarse mutuamente para aquietar la angustia que provocan los retos escépticos (p. 173).

Concretamente, la paradoja escéptica con la que inicia el volumen se basa en el principio de clausura, también denominado de transmisión del conocimiento (Nozick, 1981). De acuerdo con este principio, si conozco una proposición $P$, y ésta implica mediante un proceso de inferencia válido la proposición Q, entonces también conozco Q (p. 13). Éste es un principio lógico muy relevante, dado que permite una ampliación fiable del conocimiento, el problema es que además de las proposiciones empíricas cotidianas parece que podemos incluir otras más polémicas, como aquellas que van ligadas a famosas hipótesis escépticas, por ejemplo, la de que podríamos ser un cerebro en una cubeta, conectado a un computador que generase estímulos sensoriales semejantes a los que actualmente tenemos, aunque careciésemos de cuerpo y no hubiese un entorno real que los suscitase (Putnam, 1990). En ese sentido, no podríamos decir que sabemos que no somos cerebros en una cubeta, pero entonces, por el principio de clausura, tampoco podríamos aseverar que, por ejemplo, tenemos manos. ${ }^{3}$

Pritchard entiende de manera un tanto especial, y cuestionable, el principio de clausura, dado que en su caso habla de conocimiento racionalmente fundamentado (p. 23), cosa que sin duda excluiría gran parte de nuestro saber ordinario, para el que carecemos de ese estricto fundamento (cuyos requisitos tampoco se esclarecen con detalle en

3 Hacemos alusión aquí a las bien conocidas proposiciones formuladas por Moore como ejemplo de certeza inasequible a la duda escéptica, como "Sé que tengo dos manos" (Moore, 1962). 
el texto). Sea como fuere, tal caracterización no es casual, después de todo, de acuerdo con el autor, dicho argumento escéptico expone las consecuencias de una tesis más general, la de la aparente universalidad de la evaluación racional (p. 55). Esto es, el hecho de que, gracias al difícilmente cuestionable principio de clausura, podamos avanzar en nuestras evaluaciones, ampliando nuestro conocimiento racionalmente fundamentado, sin límite teórico alguno (aunque existan, claro está, limitaciones prácticas). En suma, dicha tesis podría conducirnos del ámbito ordinario al de los compromisos explícitamente antiescépticos más generales, como el de la existencia del mundo externo, pero eso es precisamente lo que cuestionan los argumentos escépticos, valiéndose del mismo principio de clausura.

Por otro lado, en cuanto a la otra gran paradoja escéptica expuesta por Pritchard en el segundo capítulo de su libro, cabe indicar que se basa en el principio de infradeterminación (que no es sino una reformulación del clásico problema de la aparalaxia, planteado a los dogmáticos por parte de la Academia escéptica helenística, aunque eso se le escapa a Pritchard). ${ }^{4}$ De acuerdo con éste, aunque creamos conocer una proposición empírica ordinaria, como la

4 Véase Cicero (2006, 2.40-2-42 y 2.83) para una formulación esquemática del argumento central de los académicos contra los estoicos. de que tenemos dos manos, carecemos de un fundamento racional para preferir esta proposición a una que enuncie una alternativa escéptica (como la ya mencionada del cerebro en una cubeta), con lo que no podríamos aseverar que conocemos de manera racionalmente fundamentada que tenemos dos manos (p. 32).

Nuevamente, según Pritchard, en este caso el problema escéptico se desarrolla a partir de una tesis más general, la del aislamiento de las razones (p. 55). De acuerdo con ésta, el fundamento de nuestras razones no es demasiado sólido y, por lo tanto, frente a la peligrosa ilimitación de la evaluación racional, lo que se destaca aquí son las limitaciones de los apoyos racionales a nuestro alcance. Sin embargo, pese a las aparentes semejanzas entre ambas paradojas, siguiendo al autor, a la primera cabe responder mediante el recurso a lo que hoy en día se conoce como "epistemología de goznes", basada en algunas de las estrategias anti-escépticas que Wittgenstein habría desplegado en Sobre la certeza, mientras que la segunda no puede resolverse del mismo modo, esto es, apelando al último Wittgenstein (p. 114).

La clave para entender esta diferencia reside en la interpretación de las ideas del último Wittgenstein que Pritchard despliega en el núcleo de su libro. Y es que, frente a la tesis 
de la universalidad de la evaluación racional, que permite el desarrollo escéptico del principio de clausura, Wittgenstein habría propuesto que dicha evaluación es necesariamente local, siendo las tesis anti-escépticas ejemplos de proposiciones, o compromisos, que no constituyen creencias y que evaden cualquier tipo de evaluación racional, porque son el marco en el que dichas evaluaciones se realizan (por ejemplo, Wittgenstein, 1988, $\S 115$ o $\S 125$, entre muchos otros). Las inferencias válidas se limitarían así a ampliar nuestro conocimiento de proposiciones ordinarias, pero no admitirían las hipótesis escépticas. Sin embargo, siguiendo a Pritchard, las evaluaciones pueden ser locales en esencia y aun así caer bajo las redes de la infradeterminación, no siendo capaces de proporcionar un fundamento racional para preferir la proposición ordinaria a la hipótesis escéptica alternativa.

No obstante, pese a la detallada argumentación que adelanta el autor, está lejos de ser claro por qué las propuestas de la "epistemología de goznes" no bastarían para dar una respuesta, al menos en principio, al reto de la paradoja de la infradeterminación. Después de todo, si bien es cierto que en Sobre la certeza carecemos de elementos para distinguir entre una creencia fruto de la interacción usual con el entorno, con un contenido proposicional empírico ordinario, y la creencia propia de un escenario escéptico como el anteriormente mencionado, sin embargo, dichas creencias, y el conocimiento resultante, se asientan sobre compromisos-gozne supuestamente inalcanzables para las hipótesis del escepticismo radical (Wittgenstein, 1988, §250). En ese sentido, resulta posible favorecer la creencia ordinaria frente a la alternativa escéptica, dadas las garantías que nos ofrece la certeza animal, incuestionable, de los compromisos-gozne en los que se asienta la primera (Wittgenstein, 1988, \$39).

Con esta crítica de fondo podemos encarrilar los últimos capítulos del libro de Pritchard, dedicados a la exposición de su solución al problema de la paradoja de la infradeterminación. Como ya indicamos, el autor se inclina por la propuesta de McDowell, según la cual el disyuntivismo epistémico nos permite afirmar que en los casos paradigmáticos gozamos de un conocimiento (p. 124) a la vez fáctico y reflexivo (después de todo la propuesta general de Pritchard es de corte internista, por ser ésta, según el autor, la interpretación más cercana a nuestras prácticas e intuiciones epistémicas cotidianas [pp. 16-17]). En ese sentido, hipótesis escépticas como la de la intuición del nuevo genio maligno 
Pritchard, D. (2016). Epistemic Angst. Radical Skepticism and the Groundlessness...

(p. 59), con dos agentes epistémicos, uno en condiciones normales y otro en una situación indistinguible de la primera, pero preso de un escenario escéptico, recibirían una respuesta tajante de parte del disyuntivismo. Frente a la interpretación tradicional de dicha situación hipotética, la propuesta disyuntivista pondría las creencias del agente en condiciones normales por delante de las del agente engañado por el nuevo genio maligno.

Sea como fuere, tales apreciaciones revisten un carácter problemático. En primer lugar, porque un desarrollo alternativo de la epistemología de goznes quizá proporcionase una solución a la paradoja de la infradeterminación, en el sentido apuntado previamente en nuestra reseña. $Y$, en segundo lugar, porque el propio Pritchard, como ya apuntamos, se sitúa dentro de lo que denomina estrategias minimizadoras a la hora de resolver los problemas escépticos. Así, de acuerdo con dicha orientación, y en contraste con lo que llama estrategias revisionistas, se entiende que las paradojas escépticas surgen de una mala concepción filosófica, y pueden resolverse apelando a nuestras intuiciones y prácticas ordinarias (de ahí la toma de partido por una solución dual de tipo internista y el rechazo de las influyentes propuestas externistas de solución a los retos escépticos). Pero dista de ser evidente que la propuesta de McDowell sea menos teórica que la intuición del nuevo genio maligno a la que responde (pp. 135, 142). En realidad, podría decirse que la postura ordinaria favorece intuiciones como ésta, que generan problemas escépticos de difícil solución, y que quizá el abuso de teoría estaría del lado del disyuntivismo epistémico (Lehrer \& Cohen [1983] y Cohen [1984]).

Para concluir, cabe decir que, pese a que Epistemic Angst es un libro muy valioso, no es claro que responda a todo tipo de angustia epistémica. De hecho, las formulaciones clásicas del trilema de Agripa, o aquellas que han de ver con el desacuerdo irresoluble (Sextus Empiricus, 1996), difícilmente encontrarán respuesta en una obra que se centra especialmente en el moderno problema de la existencia del mundo externo (y que olvida, o deja de lado, el carácter terapéutico del propio escepticismo antiguo, que se proponía como solución a la angustia que produce, epistémica y moralmente, el dogmatismo en sus diversas variantes).

Finalmente, ni la supuesta solución de Wittgenstein es seguro que lo sea, dado que resulta posible racionalizar nuestros compromiso-gozne (de hecho, lo hacemos todo el tiempo, y el propio Wittgenstein lo admite), con lo que cualquiera de las proposiciones que constituyen el 
trasfondo de nuestra certeza animal puede ser cuestionada y convertida en susceptible tanto de conocimiento, como de duda (Wittgenstein, 1988, §96). Ni tampoco es claro que la respuesta del disyuntivismo epistémico termine siendo satisfactoria, como se pretende en libro de Pritchard, puesto que un escepticismo radicalmente formulado bien podría cuestionar el supuesto carácter fáctico y reflexivamente accesible de nuestras proposiciones empíricas ordinarias.

\section{Referencias}

Alston, W. P. (1986). Internalism and Externalism in Epistemology. Philosophical Topics, 14, 68-110.

Cicero. (2006). On Academic Scepticism (C. Brittain, Trad.). Indianapolis \& Cambridge: Hackett.

Cohen, S. (1984). Justification and Truth, Philosophical Studies, 46, 279-96.

Coliva, A. \& Moyal-Sharrock, D. (2016) (Eds.). Hinge Epistemology. Leiden: Brill.

Lehrer, K. \& Cohen, S. (1983). Justification, Truth, and Coherence. Synthese, 55, 191-207.

McDowell, J. (1995). Knowledge and the Internal.Philosophy and Phenomenological Research, 55, 877-93.
Moore, G. E. (1962). Proof of an External World. En G. E. Moore. Philosophical Papers (pp. 126-48). New York: Collier Books.

Nozick, R. (1981). Philosophical Explanations. Oxford: Oxford University Press.

Pritchard, D. (2016a). Epistemic Angst. Radical Skepticism and the Groundlessness of Our Believing. Princeton \& Oxford: Princeton University Press.

Pritchard, D. (2016b). The Sources of Scepticism. International Journal for the Study of Skepticism, 6, 203-27.

Putnam, H. (1990). Razón, verdad e historia (J. M. E. Cloquell, Trad.). Madrid: Tecnos.

Sextus Empiricus (1996). The Skeptic Way (B. Mates, Trad.). New York \& Oxford: Oxford University Press.

Strawson, P. F. (2003). Escepticismo y naturalismo: algunas variedades (S. Badiola, Trad.). Madrid: A. Machado Libros.

Williams, M. (1991). Unnatural Doubts. London: Blackwell.

Wittgenstein, L. (1988). Sobre la certeza. (J. L. Prades \& V. Raga, Trad.). Barcelona: Gedisa.

Wright, C. (2004). Warrant for nothing (and foundations for free)? The Supplementary Volume of the Aristotelian Society, 78, 167-212. 